\title{
Differentiation of Toxic and Non-Toxic Leaves of Jatropha curcas L. Genotypes by Leaf Spray Mass Spectrometry
}

\author{
Igor Pereira, ${ }^{a}$ Thays $C$. de Carvalho, ${ }^{a}$ Wanderson Romão, ${ }^{b}$ Paulo R. Filgueiras, ${ }^{b}$ \\ Bruno G. Laviola, ${ }^{c}$ Clenilson M. Rodrigues, ${ }^{c}$ Patrícia V. Abdelnurc and Boniek G. Vaz ${ }^{*, a}$ \\ anstituto de Química, Universidade Federal do Goiás, 74690-970 Goiânia-GO, Brazil \\ ${ }^{b}$ Departamento de Química, Universidade Federal do Espírito Santo, 29075-910 Vitória-ES, Brazil
}

${ }^{c}$ Embrapa Agroenergia, 70770-901 Brasília-DF, Brazil

\begin{abstract}
Jatropha curcas L. is an oil crop that has been studied as a potential source of biodiesel. A high protein pie is produced as a byproduct of the biodiesel production, which could be used as animal feed. However, the pie has toxic compounds, as phorbol esters and other toxins, which prevents the use as animal feed. For this reason, Embrapa (Brazilian Agricultural Research Corporation) has been working in genetic breeding to develop non-toxic J. curcas genotypes. To evaluate this process, a simple and fast analytical technique was employed to obtain responses in a short time. Leaf spray (LS) is a recent ambient ionization mass spectrometry technique in which the sample itself serves as support and ion source. Here, toxic and non-toxic J. curcas leaves were differentiated by LS using a linear ion trap mass spectrometer and partial least squares discriminant analysis (PLS-DA) model chemometrics. It was possible to differentiate toxic and non-toxic leaves and to identify the $\mathrm{m} / \mathrm{z}$ values that contribute to discrimination between the groups.
\end{abstract}

Keywords: ambient mass spectrometry, PLS-DA, discrimination analysis

\section{Introduction}

Jatropha curcas L. is a Euphorbiaceae of great interest to biofuels production due to its low production cost, hardiness, adaptability, drought resistance and high oil content in its seeds. ${ }^{1}$ To add value to the productive chain of biodiesel, the pie resulting from the extraction of oil from seeds, is being studied as a potential agent of animal feed due to its high protein value. ${ }^{2}$ However, because some toxins and anti-nutritional factors, pie has not been used yet as animal feed. The major toxic compounds are the phorbol esters, ${ }^{3}$ tetracyclic diterpenes with biological activities such as tumor promotion, platelet aggregation, apoptosis, cell differentiation and other adverse metabolic effects. ${ }^{4}$ Additionally, other toxic compounds are reported in leaves, seeds and pie of $J$. curcas, such as trypsin inhibitors, tannins, saponins, phytates, lectins and curcin. ${ }^{3}$

Researchers are working on J. curcas to produce nontoxic crops. In Brazil, researches at Embrapa (Brazilian Agricultural Research Corporation) are using genetic breeding approaches to obtain a $J$. curcas genotype fully

*e-mail: boniek@ufg.br well-adapted in the country's growing conditions, with good productivity, resistant to pests and diseases and not presenting toxic compounds. To monitor the efficiency of the detoxification process based on genetic breeding carried out by Embrapa, it is necessary to employ analytical techniques that provide precise and accurate information in a short time. Although HPLC-UV (high performance liquid chromatography ultraviolet) is often used in the routine analysis of toxic compounds in J. curcas, ${ }^{5-7}$ there are few studies using liquid chromatography mass spectrometry (LC-MS) ${ }^{8-10}$ However, these methods require sample preparation and separation steps, resulting in a time-consuming and laborious method. So, there is a lack of studies to determine these compounds quickly and comprehensively.

The development of ambient ionization/desorption techniques brought simplified alternative for detection and quantification of analytes directly from their natural ambient without the need of separation steps and with little or no sample preparation. ${ }^{11}$ Desorption electrospray ionization (DESI) ${ }^{12}$ and direct analysis in real time $(\mathrm{DART})^{13}$ are precursors techniques and protagonists of this revolution in mass spectrometry. After these two techniques 
has emerged, a large number of techniques with the same purpose was emerging. ${ }^{11,14}$

An ambient ionization technique was recently developed, the leaf spray (LS), a technical variant of paper spray ionization. ${ }^{15}$ In the LS-MS technique, ions are generated directly from plant tissues ${ }^{16}$ and no support is needed to deposit the sample because the plant acts simultaneously as sample and support for ions generation. The plant leaf is wetted with solvent, and a high voltage is applied in the leaf, producing ions to the mass spectrometer. Ions can be generated without adding solvent in plant tissue due to the natural juice present in fruit and vegetables, although spectra with more intense signals and better $\mathrm{S} / \mathrm{N}$ ratio can be obtained when the solvent is added. ${ }^{17}$ LS-MS has been used in many applications, such as detection of ursolic and oleanolic acids and their oxidation products in medicinal plant Ocimum sanctum ${ }^{18}$ glycosides analysis from Stevia leaves, ${ }^{19}$ profile analysis of saccharides, glycoalkaloids, organic acids, and glucosinolates in living plants and fresh fruits, ${ }^{20}$ and quantification of pesticide in fruits and vegetables. ${ }^{17}$ LS-MS provides simple and fast analysis, with little or no sample preparation.

In this paper, we describe the combination of an easily and simple ionization method, leaf spray mass spectrometry, with PLS-DA (partial least squares discriminant analysis) to create accurate and robust model to differentiate toxic and non-toxic J. curcas genotypes based on low-resolution mass spectra profile.

\section{Experimental}

\section{Material and samples}

HPLC-grade methanol was purchased from SigmaAldrich (Steinheim, Germany). The leaves of J. curcas genotypes were provided by Embrapa Agroenergia (Brasilia, DF, Brazil). Leaves were selected from 40 genotypes, of which 16 were toxic and 24 non-toxic. ${ }^{21}$

\section{Leaf spray-MS}

$J$. curcas leaves were cut in the equilateral triangle shape with $1 \mathrm{~cm}$ sides. A high voltage $(3.5 \mathrm{kV})$ was applied to the base of each triangular leaf previously wetted with $10 \mu \mathrm{L}$ of solvent $(0.1 \%$ formic acid in methanol). A charged microdroplets spray goes directly into mass spectrometer. Leaf was positioned about $4 \mathrm{~mm}$ from the MS input. Experiments were performed in triplicate. Mass spectra were recorded in the positive mode, $\mathrm{LS}(+)$. Other parameters used were: tube lens: $109 \mathrm{~V}$; capillary voltage: $43 \mathrm{~V}$; capillary temperature: $275{ }^{\circ} \mathrm{C}$; scan range: $100-1200 \mathrm{~m} / \mathrm{z}$. The experiments were performed using the mass spectrometer LTQ XL ${ }^{\text {TM }}$ Ion Trap Linear (Thermo Scientific, San Jose, USA). To identify the major ions in the toxic and non-toxic leaves of $J$. curcas genotypes, a high-resolution MS was employed, the Q Exactive ${ }^{\mathrm{TM}}$ Hybrid Quadrupole-Orbitrap (Thermo Scientific, San Jose, USA). The parameters used were: resolution: 140,000; spray voltage: $3.5 \mathrm{kV}$; average of 3 micro-scans for each spectrum; capillary temperature: $275{ }^{\circ} \mathrm{C}$; S-lens RF Level: $50 \%$. The spectra were processed by the Xcalibur Analysis software package (version 2.0, Service Release 2, Thermo Electron Corporation). Molecular formula was acceptable only when the average differences between theoretical and experimental masses were less than $1.0 \mathrm{ppm}$. Molecular formula search was done using ${ }^{12} \mathrm{C},{ }^{1} \mathrm{H}$, ${ }^{16} \mathrm{O},{ }^{14} \mathrm{~N},{ }^{23} \mathrm{Na}$ and ${ }^{39} \mathrm{~K}$ isotopologue ions.

\section{Chemometrics}

The chemometrics analysis was performed using PLS-DA model. To construct the model, 40 samples, 16 toxic and 24 non-toxic leaves, were divided into training (28 samples) and test (12 samples) sets using the duplex algorithm. ${ }^{22}$ The mass spectra dataset were autoscaled and the model was construct with five latent variables determined by leave-one-out cross-validation method. The percentage ratio of the ion intensities in the mass spectra was employed in the model construction. The threshold of discrimination between classes of samples was defined according to Bayes method. ${ }^{23}$ The forecasting results of classification models were evaluated for sensitivity, specificity, accuracy and prevalence. ${ }^{24}$ The sensitivity indicates the probability model to detect a toxic sample, since the sample is actually toxic; specificity reflects the probability model to identify correctly a non-toxic sample, when it really is non-toxic; accuracy is the model's ability to classify correctly a toxic and nontoxic sample; the prevalence is split between the positive predictive value, which reflects the probability that the model is wrong when it identifies a sample as toxic, and negative predictive value, which reflects the probability that the model is wrong when it identifies a sample as non-toxic. From regression coefficients of the PLS-DA, the most important variables, $m / z$, were selected and a new model was built. All calculations were performed in Matlab® 7.8.0 software using the classification toolbox 3.0.25

\section{Results and Discussion}

LS(+)-MS was used to differentiate between 16 toxic and 24 non-toxic leaves of $J$. curcas genotypes using a LTQ ion trap linear mass spectrometer. Ions were generated directly from the leaf tissue, without any sample 
preparation. Figure 1 illustrates the scheme of LS-MS homemade source developed.

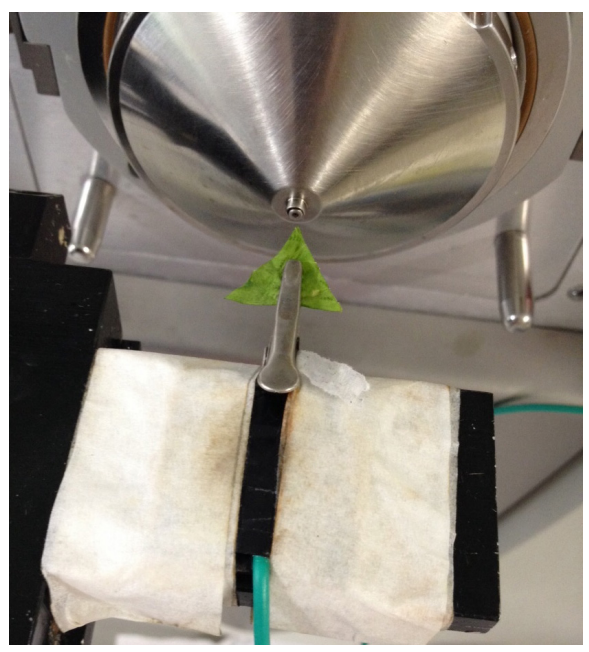

Figure 1. Schematic of leaf spray-MS homemade source.

Figure 2 shows the mass spectra of all toxic (Figure 2a) and non-toxic (Figure 2b) leaves. Most of the ions were detected in both set, however, mass spectra of toxic leaves have shown more compounds. Some low-resolution mass spectra of toxic (Figure S1) and non-toxic (Figure S2) leaves are shown in the Supplementary Information. Mass spectra for toxic and non-toxic exhibited various common ions.
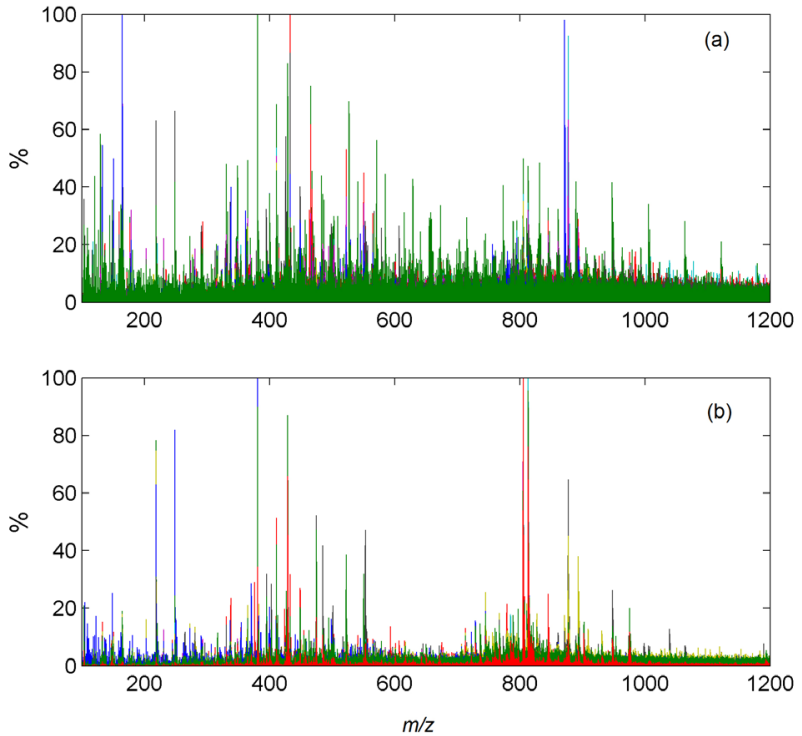

Figure 2. Positive leaf spray mass spectra of (a) all toxic leaves; (b) all non-toxic leaves.

To identify the most intense ions, positive mass spectra of J. curcas leaves were recorded with high-resolution mass spectrometer Q-Exactive Hybrid Quadrupole-Orbitrap. Figure 3a shows a LS(+)-Orbitrap mass spectrum of a toxic leaf and Figure $3 \mathrm{~b}$ shows a mass spectrum of a non-toxic leaf. Similarly to the low-resolution mass spectra, the high-resolution mass spectra for toxic and non-toxic also exhibited various ions in common. The ions of $m / z 219$,
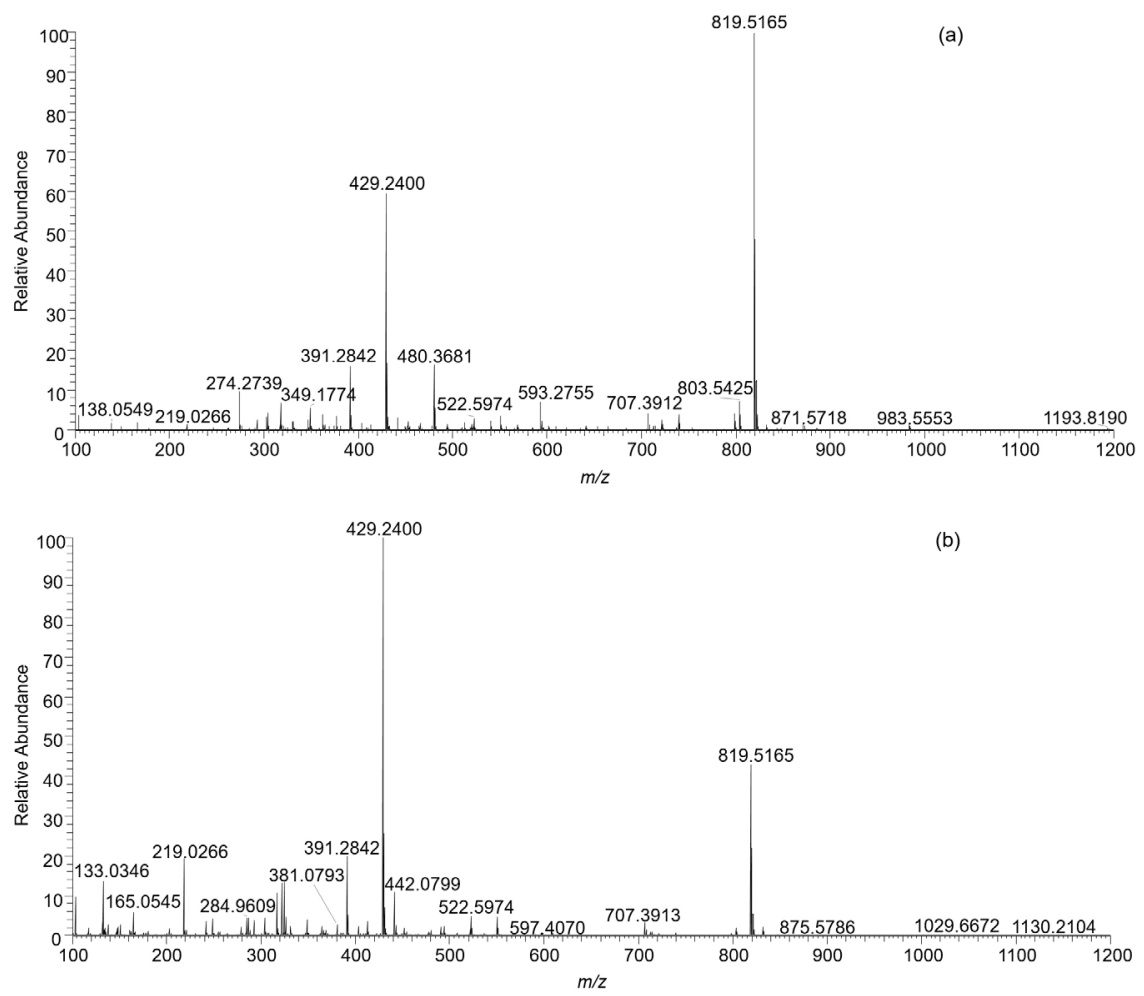

Figure 3. LS(+)-Orbitrap mass spectrum of (a) toxic leaf; (b) non-toxic leaf. 
$391,429,480$ and 819 were some of the most intense in the mass spectra of all 40 leaves analyzed.

Table 1 shows the LS(+)-Orbitrap MS molecular formula assignments of various ions detected in the toxic and non-toxic leaves of $J$. curcas genotypes. The most intense ions at $\mathrm{m} / \mathrm{z}, 391,429$ and 819 were detected as phthalate, that are contaminant compounds. Phthalates are common plasticizers widely used in commercial products, including laboratory equipment parts. ${ }^{26}$ The low-intensity ions at $\mathrm{m} / \mathrm{z}, 522$ and 803 were also detected as contaminant compounds, being stearyl-palmityl dimethyl ammonium and diisooctyl phthalate, respectively.

Table 1. Molecular formula assigned to ions detected in J. curcas leaves by LS(+)-Orbitrap MS

\begin{tabular}{|c|c|c|c|}
\hline $\mathrm{m} / \mathrm{z}$ & Error / ppm & $\mathrm{RDB}^{\mathrm{a}}$ & Molecular formula \\
\hline 138.05492 & -0.254 & 4.5 & $\mathrm{C}_{7} \mathrm{H}_{8} \mathrm{NO}_{2}$ \\
\hline 199.16937 & 0.570 & 1.5 & $\mathrm{C}_{12} \mathrm{H}_{23} \mathrm{O}_{2}$ \\
\hline 200.03198 & 0.828 & 6.5 & $\mathrm{C}_{9} \mathrm{H}_{7} \mathrm{NO}_{3} \mathrm{Na}$ \\
\hline 219.02640 & -0.669 & 0.5 & $\mathrm{C}_{6} \mathrm{H}_{12} \mathrm{O}_{6} \mathrm{~K}$ \\
\hline 274.27393 & -0.459 & -0.5 & $\mathrm{C}_{16} \mathrm{H}_{36} \mathrm{NO}_{2}$ \\
\hline 293.06311 & -0.736 & 0.5 & $\mathrm{C}_{9} \mathrm{H}_{18} \mathrm{O}_{8} \mathrm{~K}$ \\
\hline 318.30011 & -0.505 & -0.5 & $\mathrm{C}_{18} \mathrm{H}_{40} \mathrm{NO}_{3}$ \\
\hline 349.17737 & -0.566 & 3.5 & $\mathrm{C}_{18} \mathrm{H}_{30} \mathrm{O}_{4} \mathrm{~K}$ \\
\hline 361.17746 & -0.298 & 4.5 & $\mathrm{C}_{19} \mathrm{H}_{30} \mathrm{O}_{4} \mathrm{~K}$ \\
\hline 362.08450 & -0.380 & 7.5 & $\mathrm{C}_{15} \mathrm{H}_{17} \mathrm{NO}_{8} \mathrm{Na}$ \\
\hline 363.19312 & 0.149 & 8.5 & $\mathrm{C}_{22} \mathrm{H}_{28} \mathrm{O}_{3} \mathrm{Na}$ \\
\hline 381.07925 & 0.084 & 6.5 & $\mathrm{C}_{15} \mathrm{H}_{18} \mathrm{O}_{10} \mathrm{Na}$ \\
\hline 391.28418 & -0.271 & 5.5 & $\mathrm{C}_{24} \mathrm{H}_{39} \mathrm{O}_{4}$ \\
\hline 429.24008 & -0.205 & 5.5 & $\mathrm{C}_{24} \mathrm{H}_{38} \mathrm{O}_{4} \mathrm{~K}$ \\
\hline 442.07986 & 0.074 & 20.5 & $\mathrm{C}_{25} \mathrm{H}_{13} \mathrm{~N}_{3} \mathrm{O}_{4} \mathrm{Na}$ \\
\hline 464.15244 & -0.924 & 2.5 & $\mathrm{C}_{17} \mathrm{H}_{31} \mathrm{NO}_{11} \mathrm{~K}$ \\
\hline 480.36807 & -0.583 & 4.5 & $\mathrm{C}_{28} \mathrm{H}_{50} \mathrm{NO}_{5}$ \\
\hline 505.14240 & -0.237 & 22.5 & $\mathrm{C}_{31} \mathrm{H}_{22} \mathrm{~N}_{4} \mathrm{OK}$ \\
\hline 522.59741 & 0.348 & -0.5 & $\mathrm{C}_{36} \mathrm{H}_{76} \mathrm{~N}$ \\
\hline 568.56653 & 0.367 & 0.5 & $\mathrm{C}_{36} \mathrm{H}_{74} \mathrm{NO}_{3}$ \\
\hline 570.23090 & -0.385 & 5.5 & $\mathrm{C}_{25} \mathrm{H}_{41} \mathrm{NO}_{11} \mathrm{~K}$ \\
\hline 593.27551 & -0.568 & 19.5 & $\mathrm{C}_{35} \mathrm{H}_{37} \mathrm{~N}_{4} \mathrm{O}_{5}$ \\
\hline 617.43878 & 0.008 & 4.5 & $\mathrm{C}_{35} \mathrm{H}_{62} \mathrm{O}_{7} \mathrm{Na}$ \\
\hline 623.36981 & -0.972 & 17.5 & $\mathrm{C}_{37} \mathrm{H}_{47} \mathrm{~N}_{6} \mathrm{O}_{3}$ \\
\hline 639.36603 & 0.656 & 13.5 & $\mathrm{C}_{39} \mathrm{H}_{52} \mathrm{O}_{6} \mathrm{Na}$ \\
\hline 736.31909 & 0.348 & 17.5 & $\mathrm{C}_{37} \mathrm{H}_{46} \mathrm{~N}_{5} \mathrm{O}_{11}$ \\
\hline 779.48999 & 0.011 & 4.5 & $\mathrm{C}_{38} \mathrm{H}_{71} \mathrm{~N}_{2} \mathrm{O}_{14}$ \\
\hline 803.54248 & -0.946 & 10.5 & $\mathrm{C}_{48} \mathrm{H}_{76} \mathrm{O}_{8} \mathrm{Na}$ \\
\hline 805.45728 & -0.909 & 6.5 & $\mathrm{C}_{40} \mathrm{H}_{69} \mathrm{O}_{16}$ \\
\hline 819.51654 & -0.778 & 10.5 & $\mathrm{C}_{48} \mathrm{H}_{76} \mathrm{O}_{8} \mathrm{~K}$ \\
\hline 871.57318 & -0.020 & 20.5 & $\mathrm{C}_{55} \mathrm{H}_{75} \mathrm{~N}_{4} \mathrm{O}_{5}$ \\
\hline 983.55530 & 0.319 & 7.5 & $\mathrm{C}_{49} \mathrm{H}_{84} \mathrm{O}_{18} \mathrm{Na}$ \\
\hline
\end{tabular}

${ }^{\mathrm{a}} \mathrm{RDB}$ : ring/double bond equivalent.

Due to the complexity of the data, excess of variables and similarity of mass spectra, PLS-DA chemometric model was applied to assist in the differentiation of ions related to toxic and non-toxic leaves. Figure 4 displays the regression coefficients of the PLS-DA model constructed with five latent variables. The higher coefficient intensity, the greater the importance of this variable in the model construction and consequently to discriminate toxic and non-toxic leaves samples. The horizontal line at $1.03 \times 10^{-3}$ represents a threshold for identification of the $\mathrm{m} / \mathrm{z}$ values most important for class of toxic samples, whereas horizontal line at $-1.03 \times 10^{-3}$ is the same for the nontoxic samples. These $m / z$ values are shown in Table S1 (Supplementary Information).

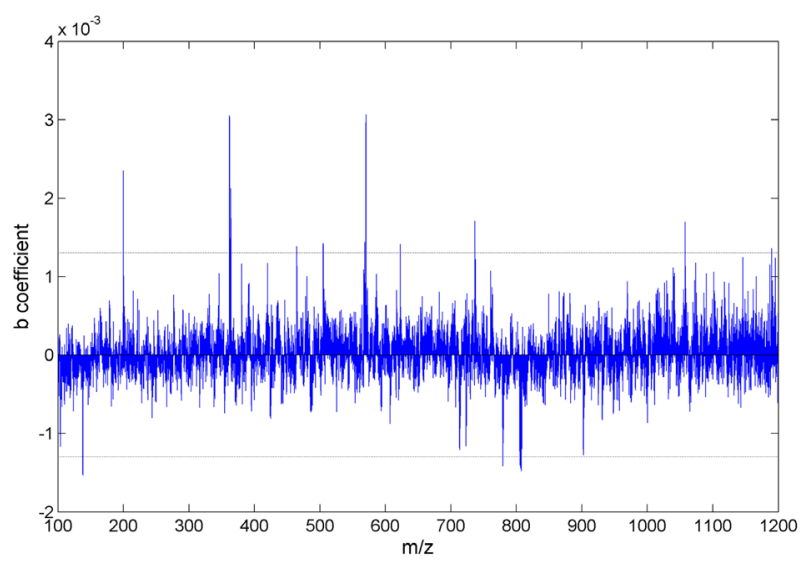

Figure 4. Regression coefficients of the PLS-DA model for the toxic and non-toxic leaves with five latent variables.

The average value of the percentage intensities of selected toxic and non-toxic samples are shown in Figure 5. Between the variables 7 to 43 , the average $m / z$ value for toxic samples is superior to non-toxic samples, while between the variables 53 to 70 , the average intensity of non-toxic samples is greater than the toxic samples.

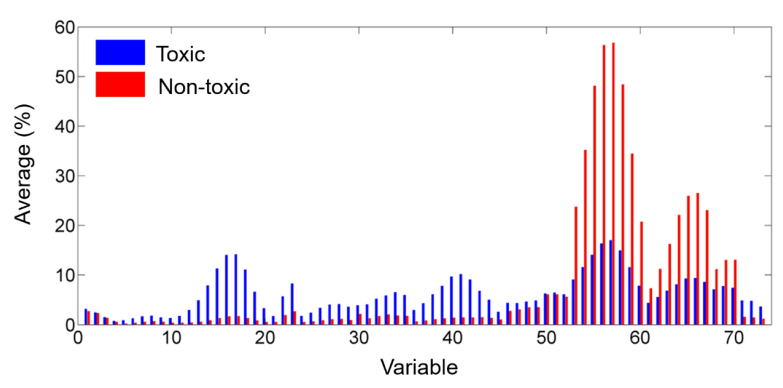

Figure 5. Average value of the percentage intensities of the more important variables identified by PLS-DA model for the toxic and non-toxic leaves. The variable number is the $\mathrm{m} / \mathrm{z}$ value of the Table S1.

From regression coefficients of the PLS-DA, the most important variables, $\mathrm{m} / \mathrm{z}$, were selected to build a new model. Figure 6 shows the results from PLS-DA model calculated with five latent variables for identification of toxic leaves samples. The y-axis represents the calculated 


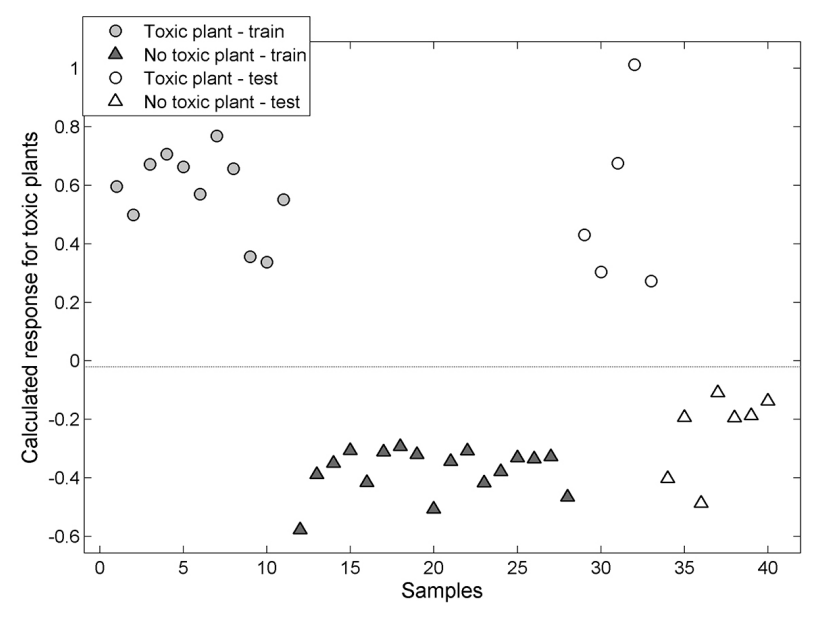

Figure 6. Calculated response of the PLS-DA model with variable selection with five latent variables for identification of toxic leaves samples. The horizontal line represents a limit to discrimination of samples.

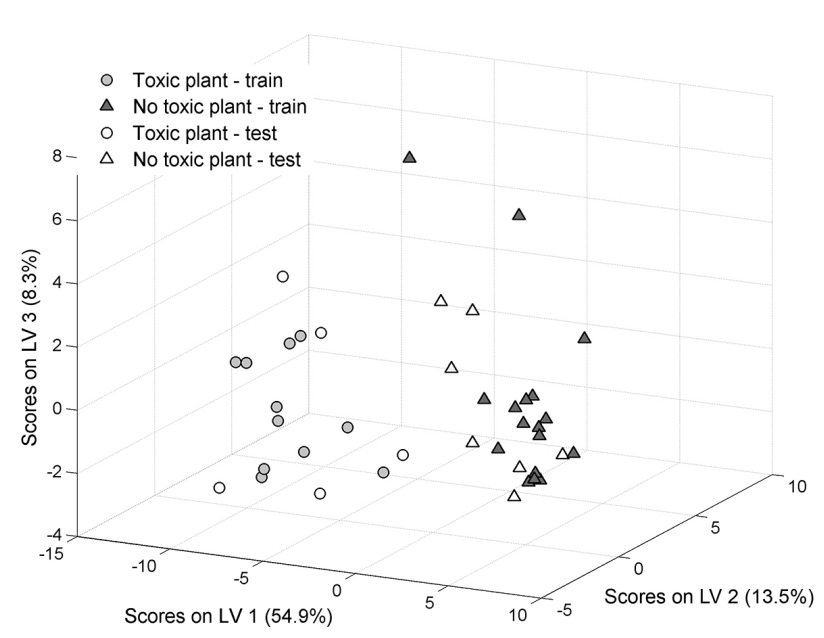

Figure 7. Scores plot for the first three latent variables (LV) of PLSDA model with variable selection applied to toxic and non-toxic leaves samples.

Table 2. Results of the statistical parameters for classification of leaves samples according to the PLS-DA model with 5 latent variables

\begin{tabular}{|c|c|c|c|c|}
\hline \multirow[t]{2}{*}{ Parameter } & \multicolumn{2}{|c|}{ All variables } & \multicolumn{2}{|c|}{ After variable selection } \\
\hline & Training / \% & Test / \% & Training / \% & Test / \% \\
\hline Sensibility & 100 & 80 & 100 & 100 \\
\hline Specificity & 100 & 100 & 100 & 100 \\
\hline Accuracy & 100 & 92 & 100 & 100 \\
\hline Positive predictive value & 100 & 100 & 100 & 100 \\
\hline Negative predictive value & 100 & 88 & 100 & 100 \\
\hline
\end{tabular}

response to identify toxic leave samples. A horizontal line was determined from training samples using the Bayes method for maximum discrimination between toxic and non-toxic leaves samples. Samples located above the horizontal line are identified as belonging to the toxic leaf group. Note that all training and testing samples were correctly classified by the PLS-DA model built with only the most important ions to discrimination between the leaves of plants toxic and non-toxic.

All the training set samples were correctly classified. Thus, their statistical parameters showed $100 \%$ efficiency (Table 2). The model with all variables applied to the test set showed $80 \%$ of sensitivity, $88 \%$ of negative prevalence and $100 \%$ of positive prevalence. However, the model with variable selection presented $100 \%$ for all parameters showing the efficiency from model built with only the most important variables.

A spatial representation of the samples is shown in Figure 7 , where $76.7 \%$ of the total variability of the spectra is represented by scores of the first three latent variables. It is observed that the non-toxic samples are less scattered in three-dimensional subspace and form a defined group. This spatial distribution, combined with the high accuracy of the model, provides the identification of the most important variables for discrimination of class samples by model regression coefficients. Samples of toxic leaves show large dispersion indicating greater variability identified in these samples.

\section{Conclusions}

Leaf spray mass spectrometry is a simple and fast method for analysis and screening of compounds in Jatropha curcas leaves without any sample preparation. Leaves of J. curcas genotypes can be differentiated between toxic and nontoxic using LS-MS associated with chemometric model PLS-DA. The scores plot discriminate the two classes of samples. Based on the model coefficients, it was possible to identify the $\mathrm{m} / \mathrm{z}$ values that contribute to discrimination between toxic and non-toxic leaves. Discrimination can be done using a routine and low resolution mass spectrometer. Thus, this paper shows a simple and efficient method for the quality control of the detoxification process in leaves of $J$. curcas genotypes. 


\section{Supplementary Information}

Supplementary information (Figure S1, Figure S2 and Table S1) is available free of charge at http://jbcs.sbq.org. br as PDF file.

\section{Acknowledgments}

The authors thank CNPq, CAPES, FAPES, FAPEG and EMBRAPA for institutional and financial support.

\section{References}

1. Makkar, H. P. S.; Becker, K.; Eur. J. Lipid Sci. Technol. 2009, 111, 773.

2. Prasad, L.; Pradhan, S.; Das, L. M.; Naik, S. N.; Appl. Energy 2012, 93, 245.

3. Makkar, H. P. S.; Becker, K.; Sporer, F.; Wink, M.; J. Agric. Food Chem. 1997, 45, 3152.

4. Goel, G.; Makkar, H. P.; Francis, G.; Becker, K.; Int. J. Toxicol. 2007, 26, 279 .

5. Devappa, R. K.; Bingham, J. P.; Khanal, S. K.; Ind. Crops Prod. 2013, 49, 211.

6. Baldini, M.; Ferfuia, C.; Bortolomeazzi, R.; Verardo, G.; Pascali, J.; Piasentier, E.; Franceschi, L.; Ind. Crops Prod. 2014, 59, 268.

7. Makkar, H. P. S.; Maes, J.; Greyt, W. D.; Becker, K.; J. Am. Oil Chem. Soc. 2009, 86, 173.

8. Ichihashi, K.; Yuki, D.; Kurokawa, H.; Igarashi, A.; Yajima, T.; Fujiwara, M.; Maeno, K.; Sekiguchi, S.; Iwata, M.; Nishino, H.; J. Am. Oil Chem. Soc. 2011, 88, 851.

9. Liu, X.; Li, L.; Li, W.; Lu, D.; Chen, F.; Li, J.; Ind. Crops Prod. 2013, 47, 29.

10. Punsuvon, V.; Nokkaew, R.; Karnasuta, S.; ScienceAsia 2012, $38,223$.
11. Alberici, R. M.; Simas, R. C.; Sanvido, G. B.; Romão, W.; Lalli, P. M.; Benassi, M.; Cunha, I. B. S.; Eberlin, M. N.; Anal. Bioanal. Chem. 2010, 398, 265.

12. Takáts, Z.; Wiseman, J. M.; Cooks, R. G.; Anal. Chem. 2011, 83, 4508 .

13. Cody, R. B.; Laramée, J. A.; Durst, H. D.; Anal. Chem. 2005, 77, 2297.

14. Harris, G. A.; Galhena, A. S.; Fernández, F. M.; Anal. Chem. 2011, 83, 4508.

15. Wang, H.; Liu, J.; Cooks, R. G.; Ouyang, Z.; Angew. Chem., Int. Ed. 2010, 49, 877.

16. Liu, J.; Wang, H.; Cooks, R. G.; Ouyang, Z.; Anal. Chem. 2011, 83,7608 .

17. Malaj, N.; Ouyang, Z.; Sindona, G.; Cooks, R. G.; Anal. Methods 2012, 4, 1913.

18. Sarkar, D.; Srimany, A.; Pradeep, T.; Analyst 2012, 137, 4559.

19. Zhang, J. I.; Li, X.; Ouyang, Z.; Cooks, R. G.; Analyst 2012, 137, 3091.

20. Peng, Y. E.; Zhang, S.; Wen, F.; Ma, X.; Yang, C.; Zhang, X.; Anal. Chem. 2012, 84, 3058.

21. Laviola, B. G.; Bhering, L. L.; Mendonça, S.; Rosando, T. B.; Albrecht, J. C.; Biosci. J. 2011, 27, 371.

22. Snee, R. D.; Technometrics 1997, 19, 415.

23. Pérez, N. F.; Ferré, J.; Boqué, R.; Chemom. Intell. Lab. Syst. 2009, 95, 122.

24. Neto, A. C.; Oliveira, E. C. S.; Lacerda Jr., V.; Castro, E. V. R.; Romão, W.; Silva, R. C.; Pereira, R. G.; Sten, T.; Filgueiras, P. R.; Poppi, R. J.; Fuel 2014, 135, 387.

25. http://michem.disat.unimib.it/chm/, accessed in December 2016.

26. Qi, S. H.; Xu, Y.; Xiong, H. R.; Qian, P. Y.; Zhang, S.; World J. Microbiol. Biotechnol. 2009, 25, 399.

Submitted: October 31, 2016

Published online: December 20, 2016 